\title{
IbM SMP "PERINGKAT SEDANG" DI KOTA YOGYAKARTA PENGUATAN PROFESIONALISME GURU MATEMATIKA DAN IPA BERBASIS PEER TEACHING DI WILAYAH KOTA YOGYAKARTA
}

\author{
Oleh: \\ Agustina Sri Purnami', Yuli Prihatni² \\ 1,2Universitas Sarjanawiyata Tamansiswa \\ 1purnami_mat@yahoo.com
}

\begin{abstract}
Abstrak
Kegiatan pembinaan bagi guru-guru matematika dan IPA SMP 'Peringkat Sedang' berbasis peer teaching di wilayah Kota yogyakarta bertujuan untuk mewujudkan budaya akademik yang sehat bagi terselenggaranya proses pembelajaran. Guru-guru kurang antusias dalam menanggapi diskusi yang berkenaan dengan materi, terutama materi yang berkaitan dengan tes olimpiade matematika dan IPA. Untuk itu guru perlu dilatih dengan penyegaran kompetensi pedagogik dan kompetensi profesional. Metode pembinaan guru yang dilakukan melalui peer teaching dan pelatihan. Kegiatan ini menghasilkan (1) Pendalaman materi matematika dan IPA, (2) Penyusunan modul dan strategi penyelesaian soal-soal matematika dan IPA yang diselaraskan dengan soal tes olimpiade, (3) Pendampingan guru-guru dalam pembimbingan kepada siswanya untuk menyiapkan sebagai calon peserta olimpiade matematika dan IPA. (4) Kompetensi pedagogik dan kompetensi profesional guru meningkat secara signifikan, (5) Kualitas guru matematika dan IPA SMP meningkat secara signifikan. Diharapkan kegiatan serupa dapat diteruskan karena kegiatan peer teaching melatih guru berani menyampaikan gagasannya di hadapan para guru.
\end{abstract}

Kata Kunci: Peer Teaching, Pelatihan Guru, Tes Olimpiade Matematika dan IPA

\begin{abstract}
The guidance activities for math teachers and science of SMP 'moderate' level based on peer teaching in Yogyakarta City area aims to create a healthy academic culture for the implementation of learning process. Teachers are less enthusiastic in responding to discussions about the material, especially material related to mathematics and science Olympiad test. Teachers need to be trained with a refresher of pedagogic competence and professional competence. Teacher coaching methods are done through peer teaching and training. This activity resulted in (1) the deepening of mathematics and science materials, (2) Preparation of modules mathematics and science problem solving and strategies that were aligned with the Olympiad test questions, (3) Assistance of teachers in the guidance to their students to prepare as a candidate participants of mathematics and science Olympiad. (4) the pedagogical competence and professional competence of teachers increased significantly, (5) the quality of math teachers and the science of junior high school increased significantly. It is expected that similar activities can be continued because peer teaching activities train teachers to dare to convey their ideas in front of teachers.
\end{abstract}

Keywords: Peer Teaching, Teacher Training, Mathematics and Science Olympiad

\section{PENDAHULUAN}

Mengkaji kualitas pendidikan tidak dapat terlepas dari guru, karena guru menempati posisi penting dalam pendidikan dan memberikan kontribusi yang tinggi untuk peningkatan hasil belajar siswa. Guru masih menjadi ujung tombak dalam pendidikan, maka pemerintah melalui Undang-Undang Republik Indonesia, Nomor 14, Tahun 2005 tentang Guru dan Dosen (UUGD) menyebutkan bahwa guru dan dosen mempunyai fungsi, peran, dan kedudukan yang sangat strategis dalam pembangunan nasional di bidang pendidikan. Guru adalah pendidik professional dengan tugas utama mendidik, mengajar, membimbing, mengarahkan, melatih, menilai, dan mengevaluasi peserta didik (UU RI No 14 Tahun 2005). Di Indonesia guru menjadi ujung tombak dalam pendidikan, artinya kualitas luaran pendidikan sangat ditentukan oleh gurunya. 
Berdasarkan hasil servey awal terhadap beberapa guru matematika dan IPA di SMP dengan perolehan 'Peringkat UN Sedang', diperoleh bahwa guru kurang antusias saat diskusi mengenai materi matematika, apalagi materi matematika yang diorientasikan pada soal olimpiade. Hasil wawancara dengan kepala sekolah diperoleh bahwa kekurangantusiasan guru saat diskusi dikarenakan sekolah tersebut tidak pernah mengikutkan siswanya dalam ajang olimpiade matematika dan IPA SMP. Guru perlu mendapat pembinaan dan pelatihan bagaimana strategi menyusun instrument tes yang diselaraskan dengan tes olimpiade matematika dan IPA beserta strategi penyelesaiannya (Anderson, 2004). Guruguru matematika dan IPA SMP yang dipilih dari sekolah dengan peringkat sedang berdasarkan perolehan nilai ujian nasional. Guru perlu dilatih dan dibina strategi penyusunan instrument tes matematika dan IPA yang diselaraskan dengan tes olimpiade matematika dan IPA beserta strategi penyelesaiannya (Bergo, 2010). Dengan kegiatan ini guru akan menghadapi tantangan sehingga guru akan antusias dalam mengantarkan siswanya untuk mengikuti ajang olimpiade.

\section{Analisis Situasi}

Kondisi siswa SMP 'peringkat sedang' memiliki kemampuan akademik cenderung rendah, hal demikian mengakibatkan guru merasa sulit untuk mengajak siswa melakukan diskusi. Akibatnya guru kurang tertantang memajukan siswanya. Guru perlu memilih strategi dalam menghadapi kondisi siswa yang kemampuan akademiknya cenderung kurang, maka guru perlu dilatih untuk meningkatkan kompetensi pedagogik dan kompetensi profesional.

Kegiatan ini melibatkan lima sekolah perigkat sedang, yaitu: SMP N 3 Yogyakarta, SMP N 12 Yogyakarta, SMP N 14 Yogyakarta, SMP TD Jetis, dan SMP TD lbu Pawiyatan. Kelima sekolah tersebut memiliki permasalahan yang serupa. Permasalahan terletak dari input calon siswa yang rata-rata memiliki kemampuan akademik cenderung rendah. Akibatnya semangat belajar para peserta didiknya juga rendah. Untuk itu para guru harus memilih strategi pembelajaran untuk membimbing para peserta didik. Kondisi demikian menyebabkan guru kurang antusias mengajak siswanya untuk ikut dalam kompetisi di ajang yang lebih tinggi, misalnya mengikutkan dalam ajang olimpiade. Untuk itu, para guru sangat perlu diberi penyegaran. Karena guru merasa tidak ada tantangan, maka guru perlu diberi stimulus agar guru merasa tertantang untuk membawa siswanya mengikuti ajang olimpiade matematika dan IPA. Salah satu stimulus yang diberikan adalah memberi pembinaan dengan pelatihan penyusunan instrument tes yang diselaraskan dengan tes olimpiade matematika dan IPA beserta strategi penyelesaiannya. Kegiatan pembinaan meliputi: (1) Pembimbingan penyusunan instrument tes yang variatif, terutama soal yang sifatnya tidak rutin dan memerlukan pemecahan masalah dengan kemampuan analitis yang lebih tinggi, (2) Pendalaman materi matematika dan IPA, (3) Petalihan strategi penyelesaian soal-soal matematika dan IPA yang diselaraskan dengan soal tes olimpiade, (4) Pendampingan guru-guru dalam pembimbingan kepada siswanya untuk menyiapkan sebagai calon peserta olimpiade matematika dan IPA.

\section{METODE PELAKSANAAN}

Berangkat dari permasalahan yang dihadapi guru yaitu guru merasa kurang tertantang dalam pembelajaran, maka perlu dicari solusi pemecahannya. Metode yang digunakan adalah diskusi terhadap permasalahan melalui peer teaching (pembelajaran terhadap teman sejawat), guru diberi pelatihan menyusun instrumen tes yang disertai dengan pembahasannya soalsoal yang berorientasi pada tes olimpiade matematika dan IPA. Untuk meningkatkan kompetensi pedagogik, guru diberi permasalahan yang harus dipecahkan melalui peer teaching, diskusi bersama peserta pelatihan dan pelatih.

Metode pelaksanaan dalam kegiatan ini adalah pelatihan untuk meningkatkan kompetensi pedagogik dan kompetensi profesional melalui diskusi pemecahan masalah, masalah dibawa dari para guru dan dari pelatih yang berorientasi pada tes olimpiade matematika dan IPA, praktek mengajar atau peer teaching, pembahasan peer teaching, penyampaian materi dari pelatih maupun dari para peserta pelatihan,. Sehingga kegiatan penyegaran menjadi sangat hidup dan membuat peserta bersemangat. Tantangan yang diberikan guru, kerangka pemecahan masalah sebagai berikut.

1. Sebelum pelatihan, para guru peserta pelatihan diberi tes untuk mengetahui 
kompetensi pedagogik dan kompetensi profesional melalui kegiatan peer teaching.

2. Dalam pelatihan guru diberi permasalahan yang sifatnya tidak rutin, yaitu yang berorientasi pada tes olimpiade matematika dan IPA.

3. Guru diajak diskusi melalui peer teaching.

4. Hasil pembelajaran melalui peer teaching ditanggapi dan didiskusikan di antara peserta pelatihan dan pelatih.

5. Hasil diskusi untuk memperbaiki penampilan danam peer teaching lanjutan.

6. Kegiatan pelatihan ditutup dengan tes melalui kegiatan Sebelum pelatihan, para guru peserta pelatihan diberi tes untuk mengetahui kompetensi pedagogik dan kompetensi profesional melalui kegiatan peer teaching lagi.

Kegiatan pengabdian kepada masyarakat terdiri dari dua orang, namun dalam pelaksanaan di lapangan dibantu oleh dua orang lagi, jadi kegiatan ini dilaksanakan oleh empat dosen yang memiliki kompetensi di bidangnya masing-masing, yaitu dua dosen pendidikan matematika dan dua dosen pendidikan fisika. Materi yang diberikan selama kegiatan pengabdian kepada masyarakat adalah sebagai berikut.

1. Melakukan tes penjajagan penguasaan materi matematika dan IPA yang berorientasi pada tes olimpiade, yaitu penguasaan kompetensi pedagogik dan kompetensi profesional melalui peer teaching.
2. Pembahasan dan pendalaman materi dan strategi penyelesaian masalah.

3. Peer teaching lanjutan.

4. Pendampingan penyusunan tes matematika dan IPA yang berorientasi pada tes olimpiade dan strategi penyelesaiannya (Sri Purnami, 2014).

\section{Bentuk Pelaksanaan Kegiatan}

Bentuk pelaksanaan kegiatan pengabdian kepada masyarakat ini tes penjajagan penguasaan kompetensi matematika dan IPA bagi guru-guru SMP 'Peringkat Sedang' di Kota Yogyakarta melalui peer teaching tentang materi matematika. Kegiatan ini sebagai analisis kebutuhan (need analysis) pelatihan materi. Setelah dilakukan tes penjajagan maka dapat diidentifikasi kelemahan para guru yang memerlukan penyegaran materi, selanjutnya dilakukan pelatihan sebagai penyegaran materi (Widoyoko, 2012). Kegiatan yang dibutuhkan para guru adalah Penguatan Profesionalisme Guru Matematika Dan IPA Berbasis Peer Teaching Di Wilayah Kota Yogyakarta (Anderson, 2004).

\section{Waktu Efektif Pelaksanaan}

Pelaksanaan kegiatan ini memerlukan waktu selama lima bulan, seperti pada Tabel 1 .

\section{HASIL DAN PEMBAHASAN}

Hasil dari kegiatan ini dibagi dalam 5 (lima) bagian seperti dalam Tabel 2 .

Tabel 1. Waktu Efektif Pelaksanaan Kegiatan

\begin{tabular}{ccl}
\hline No. & Waktu/Bulan & \multicolumn{1}{c}{ Komponen RPP } \\
\hline 1 & April - Mei & $\begin{array}{l}\text { Koordinasi Dinas Pendidikan dan Kepala Sekolah } \\
\text { mengenai kegiatan yang akan dilakukan }\end{array}$ \\
\hline 2 & Mei & Penyusunan tes penjajagan \\
\hline 3 & Juni & $\begin{array}{l}\text { Penyelenggara memilih soal-soal matematika dan IPA dan } \\
\text { di review melalui FGD I dan II }\end{array}$ \\
\hline 4 & Juli & $\begin{array}{l}\text { Mengadakan penyegaran materi matematika dan IPA yang } \\
\text { berorientasi pada tes olimpiade }\end{array}$ \\
\hline 5 & Agustus & $\begin{array}{l}\text { Setelah mengikuti penyegaran, para guru latihan mengajar } \\
\text { di dalam kelompok kecil (peer teaching) }\end{array}$ \\
\hline $\mathbf{6}$ & Agustus & Hasil peer teaching didiskusikan \\
\hline $\mathbf{8}$ & Agustus & Penyegaran materi lanjutan \\
\hline
\end{tabular}


Tabel 2. Hasil Pelaksanaan Pembinaan Guru Matematika dan IPA SMP 'Peringkat Sedang”

\begin{tabular}{cll}
\hline No. & \multicolumn{1}{c}{ Kegiatan } & \multicolumn{1}{c}{ Hasil yang telah Dicapai } \\
\hline 1 & $\begin{array}{l}\text { Tes penjajagan dengan } \\
\text { peer teaching }\end{array}$ & $\begin{array}{l}\text { Para guru menyampaikan materi yang berorientasi pada } \\
\text { tes olimpiade. Hasilnya, opara guru kurang meguasai } \\
\text { konsep matematika dan IPA, masih bersifat mekanis dalam } \\
\text { menyelesaikan masalah. Oleh karena itu masih harus diberi } \\
\text { penyegaran }\end{array}$ \\
\hline 2 & $\begin{array}{l}\text { Pendalaman materi } \\
\text { matematika dan IPA }\end{array}$ & $\begin{array}{l}\text { Para guru sangat antusias dalam mengikuti penyegaran, } \\
\text { dan merasa mendapatkan apa yang selama ini dicari, yaitu } \\
\text { pembimbingan materi matematika dan IPA dengan sifat } \\
\text { soal tidak rutin }\end{array}$ \\
\hline 3 & Peer teaching lanjutan & $\begin{array}{l}\text { Setelah para guru mendapatkan penyegaran materi, maka } \\
\text { peer teaching yang kedua ini jauh lebih baik, terjadi diskusi } \\
\text { yang sangat hidup. Para guru bersemangat untuk maju } \\
\text { dalam meyampaikan materi yang berorientasi tes olimpiade }\end{array}$ \\
\hline 4 & $\begin{array}{l}\text { Pembahasan peer } \\
\text { teaching }\end{array}$ & $\begin{array}{l}\text { Para guru menyadari kelemahan dalam menyampaikan } \\
\text { materi matematika dan IPA dan mampu melakukan } \\
\text { perbaikan }\end{array}$ \\
\hline 5 & Pendalaman materi & $\begin{array}{l}\text { Karena para guru sangat antusias, para guru minta untuk } \\
\text { dilakukan pendalaman materi lanjutan, bahkan minta untuk } \\
\text { dilaksanakan secara rutin }\end{array}$ \\
\hline
\end{tabular}

Hasil yang telah dicapai kegiatan ini terciptanya budaya akademik pembelajaran yang berorientasi pada soal-soal yang tidak rutin, yaitu berorientasi pada tes olimpiade matematika dan IPA. Guru semakin bersemangat dengan ditunjukkan permintaan guru membentuk grup WA untuk menjalin komunikasi materi matematika dan IPA. Di samping itu para guru meminta ada kegiatan yang sifatnya rutin. Hal ini akan dimulai 11 Agustus 2017. Guru lebih terbuka wawasan keilmuan materi secara lebih konseptual. Hasil tes atau peer teaching yang diperoleh setelah mendapatkan penyegaran materi, hasilnya naik secara signifikan. Kalau sebelum mendapatkan penyegaran materi rerata kompetensi profesional dan pedagogik mencapai 2.8, setelah mendapatkan penyegaran mencapai 3.6 dengan rentang nilai 1-4.

\section{SIMPULAN DAN SARAN}

\section{Simpulan}

Sesuai dengan tujuan kegiatan ini, yaitu menciptakan budaya akademik yang sehat bagi terselenggaranya proses pembelajaran, maka guru perlu diberi penyegaran. Guru dilatih dengan penyegaran kompetensi pedagogik dan kompetensi profesional. Metode pembinaan guru yang dilakukan melalui peer teaching dan pelatihan. Kegiatan ini menghasilkan (1) Pendalaman materi matematika dan IPA, (2) Penyusunan modul dan strategi penyelesaian soal-soal matematika dan IPA yang diselaraskan dengan soal tes olimpiade, (3) Pendampingan guru-guru dalam pembimbingan kepada siswanya untuk menyiapkan sebagai calon peserta olimpiade matematika dan IPA. (4) Kompetensi pedagogik dan kompetensi profesional guru meningkat secara signifikan, (5) Kualitas guru matematika dan IPA SMP meningkat secara signifikan.

\section{Saran}

Kegiatan pelatihan model peer teaching sangat efektif untuk memberi penyegaran dan pengalaman baru bagi para guru, oleh nkarena itu pelatihan model peer teaching dapat direkomendasikan untuk dilaksanakan agar budaya akademik dapat tercipta melalui kegiatan mimbar akademik diskusi dan mempertahankan pendapatnya dengan pengalaman dan pengetahuan.

\section{DAFTAR PUSTAKA}

Anderson, L. W. 2004. Increasing Teacher Effectiveness. London \& New York: Taylor \& Francis e-Library.

Bergo, C., Jung, C., Uwe, Ch. F. 2010. Training Concept. Luxemburg: Center de Prevention des Toxicomanies.

Widoyoko, E. P. 2012. Teknik Penyusunan Instrumen Penelitian. Yogyakarta: Pustaka Pelajar. 
Sri Purnami, Ag. 2014. Peluang dan Statistika. Modul. Yogyakarta.

Undang-Undang Republik Indonesia, Nomor 14, Tahun 2005 tentang Guru dan Dosen. 